\title{
Epigenetics: An Innovative Approach for Biotechnology and Food Science
}

\author{
Medine Gulluce, Burak Alaylar, Taha Yasin Koc, and Mehmet Karadayi
}

\begin{abstract}
Recently, epigenetics has been one of the most important advances in the biology and associated fields due to its valuable potential to explain how the primary DNA sequence of an organism is affected by the environmental conditions and which changes occur in the phenotype depending on related changes. Understanding rules of epigenetics and its fundamental mechanisms is essential to get a clear comprehension for many cellular processes such as quiescence, proliferation, differentiation, migration, etc., and it enables development of new technologies for various areas especially including biology, agriculture, medicine, biotechnology and food sciences. Hence, the present study was designated to review basic principles of epigenetics, recent advances in this field and its use potential for biotechnology and food applications.
\end{abstract}

Index Terms-Biotechnology, epigenetics, food science, gene expression regulations.

\section{INTRODUCTION}

Epigenetics, initially introduced in 1942 by Conrad Waddington, is a scientific discipline whose researches mainly focus on phenotypic alterations that become under the control of various environmental stimuli [1]-[4]. In general, the term of epigenetics refers to "above or beyond genetics" and includes heritable phenotypic changes that arise independent of primary DNA sequence [5].

Each organism, whether in a unicellular or multicellular form, has to face constantly changing environment and respond to the external impulses in each moment of its life cycle. In this manner, epigenetic mechanisms of the cell play a crucial role. Recent studies showed that these mechanisms, including DNA cytosine methylation and hydroxymethylation, and acetylation, methylation, phosphorylation, ubiquitination, SUMOylation of the lysine (K) and/or arginine (R) residues of histones, generally regulate the transcription and cause a cellular response to the stimulus. The response determines fate of the affected cell by altering expression profile of the genomic information [5]. Therefore, a clear understanding of epigenetic mechanisms enables a better conception for the link between changes in expression of the genetic information within primary DNA sequence and effects of environmental factors. As a consequence of this, it allows development of novel approaches and application strategies for various fields that consist of biological systems.

Manuscript received December 5, 2013; revised March 19, 2014

Medine Gulluce and Mehmet Karadayi are with the Biology Department, Atatürk University, Erzurum, 25240 Turkey (e-mail: gullucem@atauni.edu.tr, mkaradayi@atauni.edu.tr).

Burak Alaylar and Taha Yasin Koc are with the Graduate School of Natural and Applied Sciences, Atatürk University, Erzurum, 25240 Turkey (e-mail: burakalaylar25@gmail.com, tahayasinkoc@hotmail.com).

\section{BASIC MECHANISMS OF EPIGENETICS}

Although there are several different classification types, the epigenetic mechanisms regulating gene expression are fundamentally divided into two subcategories as indirectly and directly acting mechanisms [6].

\section{A. Indirectly Acting Mechanisms}

This group contains post-transcriptional mechanisms, especially associated with non-coding RNAs (siRNA and miRNA), which affect mRNAs and inhibit synthesis of the related protein [6], [7].

\section{B. Directly Acting Mechanisms}

These mechanisms are also divided into two subgroups as chromatin remodeling and DNA modifications [6].

Chromatin remodeling basically consists of histone modifications such as acetylation, methylation, phosphorylation, S-nitrosylation, ubiquitination, SUMOylation, proline isomerization, ADP-ribosylation, deimination and non-covalent histon modifications [6]-[8].

Acetylation: Histone acetylation reactions are catalyzed by a specific enzyme group, called as histone acetyl transferases (HATs). In this reaction, an acetyl group from acetyl-CoA is transferred to the lysine $\varepsilon$-amino groups on the $\mathrm{N}$-terminal tails of histones. This causes that the condensed chromatin is transformed into a more relaxed form and it results in a transcriptional activation. Contrary to this mechanism, deacetylation reactions are catalyzed by histone deacetylases (HDACs) and NAD+-dependent sirtuin family deacetylases. This reaction generally results in re-condensation of the chromatin and inhibition of the transcription [5]-[11].

Methylation: This mechanism is mainly depending on histon methyl transferases (HMTs). Lysine and arginine residues of histones are methylated by HMTs and these modifications play crucial roles in regulation of transcription (activation, elongation or repression) and DNA repair. More recent studies also pointed out that there are several enzymes responsible for demethylation of histones [5]-[12].

Phosphorylation: This type of histone modifications is catalyzed by various specific protein kinases. In the molecular mechanism, the enzyme causes the addition of a phosphate $\left(\mathrm{PO}_{4}\right)$ group to a specific part of histone molecules. For instance, Aurora-B kinase phosphorylates the serine 10 of histone $\mathrm{H} 3$ (H3S10) during mitosis. On the other hand, it is known that phosphatases mediate removal of the phosphate groups and reverse the reaction.

Although its exact role in the epigenetic regulations is unknown, histone phosphorylation is closely related to chromosomal condensation, transcriptional regulation and DNA repair [5]-[13].

S-nitrosylation: Protein S-nitrosylation, a type of 
post-translational modification, represents the addition of an NO group to a Cys thiol to form an S-nitrosoprotein (SNO-protein). It plays an important role in cellular signaling pathways and regulation of various functional proteins [6]-[15].

Ubiquitination: In eukaryotes, ubiquitin is a small protein with 76 amino acids. One or more ubiquitin monomers covalently attach to the lysine residues of histones by ubiquitination and these are named as monoubiquitination and polyubiquitination, respectively. The related studies previously showed that monoubiquitination causes several modifications in protein functions, while polyubiquitination marks the proteins for degradation [6]-[16].

SUMOylation: This mechanism includes the addition of a small ubiquitin-related modifier protein (SUMO), approximately consists of 100 amino acids, to histones and causes a transcriptional repression [6]-[17].

Proline Isomerization: One of the recently identified histone modification mechanism is proline isomerization. It was initially reported with discovery of Frp4, a proline isomerase that accelerate switching between $\mathrm{cis}$ and trans conformations of prolines 30 and 38 on histone $\mathrm{H} 3$ tail. The conformational status of prolines regulates methylation aspects of lysine residues on histones [8].

ADP-ribosylation: Histones can be mono or poly ADP-ribosylated by ADP ribosyl transferases (ARTs) and poly (ADP-ribose) polymerases (PARPs), respectively. The former is called as mono-(ADP-ribosyl)ation and plays important roles in the cellular responses to genotoxic stress and physiological conditions (cell cycle stage, proliferation activity and degree of terminal differentiation). The latter, poly(ADP-ribosyl)ation (PARation), is related to the DNA repair mechanism [8].

Deimination: In this process, an arginine is converted to a citrulline by a related enzyme, for instance, arginines in $\mathrm{H} 3$ and $\mathrm{H} 4$ can be converted to citrullines by the PADI4 enzyme. This causes an antagonistic effect against arginine methylation due to the avoiding activity of citrullines from being methylation [8].

Non-covalent histon modifications: Histone modifications also involve various non-covalent mechanisms including intrachromosomal or interchoromosomal interactions, histone exchanges, chromatin repair and interactions with non-coding RNAs (siRNA and miRNA) [6]-[9].

DNA methylation is the most studied and well-known type of DNA modifications. DNA methylation is catalyzed by DNA methyltransferases (DNMTs), and it, together with chromatin modifications, determines most of epigenetic programs. In its molecular mechanism, DNMTs catalyze a similar reaction with HMTs in which the enzyme transfers a methyl group from S-adenosyl methionine (SAM) to the substrate (target DNA molecule) with the formation of S-adenosyl homocysteine (SAH) as a by-product [5].

DNA methylation was formerly considered as a relatively static epigenetic sign due to the chemically stability of covalent methyl groups. However, recent studies on the cellular methylome profiles of embryonic development stages suggested the presence of enzymes responsible for the removing methyl groups. For example, the recently identified TET family enzymes hydroxylate the 5-methylcytosine of DNA [5]-[19].
In this context, several examples for modifications of histones and related enzymes are summarized in Table I and Table II, respectively.

TABLE I: SEVERAL EXAMPLES FOR MODIFICATIONS IDENTIFIED ON HISTONES [20]

\begin{tabular}{lll}
\hline \hline $\begin{array}{l}\text { Chromatin } \\
\text { Modifications }\end{array}$ & Residues Modified & $\begin{array}{l}\text { Functions } \\
\text { Regulated }\end{array}$ \\
\hline \hline Acetylation & K-ac & Transcription, \\
& & Repair, Replication, \\
& Condensation
\end{tabular}

$\begin{array}{lll}\text { Methylation (lysines) } & \begin{array}{l}\text { K-me1, K-me2, } \\ \text { K-me3 }\end{array} & \begin{array}{l}\text { Transcription, } \\ \text { Repair }\end{array} \\ \text { Methylation (arginines) } & \begin{array}{l}\text { R-me1, R-me2a, } \\ \text { R-me2s }\end{array} & \text { Transcription }\end{array}$

$\begin{array}{lll}\text { Phosphorylation } & \text { S-ph, T-ph } & \begin{array}{l}\text { Transcription, } \\ \text { Repair, } \\ \text { Condensation }\end{array} \\ & \\ \text { Ubiquitination } & \text { K-ub } & \begin{array}{l}\text { Transcription, } \\ \text { Repair }\end{array}\end{array}$

\begin{tabular}{lll} 
SUMOylation & K-su & Transcription \\
Proline Isomerization & P-cis $>$ P-trans & Transcription \\
ADP-ribosylation & R-Cit & Transcription \\
Deimination & E-ar & Transcription \\
\hline
\end{tabular}

TABLE II: SEVERAL HISTONE-MODIFYING ENZYMES [20]

\begin{tabular}{|c|c|c|}
\hline Group & Enzymes & Residues Modified \\
\hline \multirow{11}{*}{ 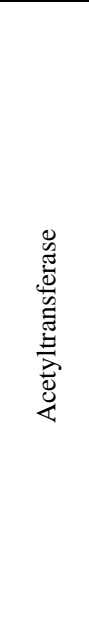 } & HAT1 & H4 (K5, K12) \\
\hline & \multirow[t]{3}{*}{ CBP/P300 } & H3 (K14, K18) \\
\hline & & $\mathrm{H} 4(\mathrm{~K} 5, \mathrm{~K} 8)$ \\
\hline & & H2A (K5), H2B (K12, K15) \\
\hline & PCAF/GCN5 & H3 (K9, K14, K18) \\
\hline & TIP60 & H4 (K5, K8, K12, K16) \\
\hline & & H3 (K14) \\
\hline & HB01 (ScESA1, SpMST1) & H4 (K5, K8, K12) \\
\hline & $\mathrm{ScSAS} 3$ & H3 (K14, K23) \\
\hline & ScSAS2 (SpMST2) & H4K16 \\
\hline & ScRTT109 & H3К56 \\
\hline 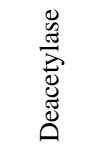 & SirT2 (ScSir2) & $\mathrm{H} 4 \mathrm{~K} 16$ \\
\hline 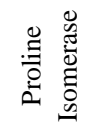 & ScFPR4 & Н3Р30, Н3Р38 \\
\hline
\end{tabular}




\section{Potential ApPlications In Biotechnology AND FOOD SCIENCE}

TABLE III: SEVERAL HISTONE-MODIFYING ENZYMES (CONTINUED)

\begin{tabular}{|c|c|c|}
\hline Group & Enzymes & Residues Modified \\
\hline \multirow{27}{*}{ 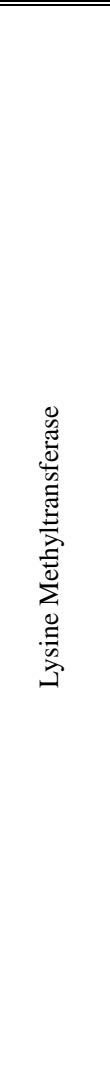 } & SUV39H1 & $\mathrm{H} 3 \mathrm{~K} 9$ \\
\hline & SUV39H2 & H3K9 \\
\hline & G9a & H3K9 \\
\hline & ESET/SETDB1 & H3K9 \\
\hline & EuHMTase/GLP & $\mathrm{H} 3 \mathrm{~K} 9$ \\
\hline & CLL8 & $\mathrm{H} 3 \mathrm{~K} 9$ \\
\hline & SpCIr4 & $\mathrm{H} 3 \mathrm{~K} 9$ \\
\hline & MLL1 & $\mathrm{H} 3 \mathrm{~K} 4$ \\
\hline & MLL2 & $\mathrm{H} 3 \mathrm{~K} 4$ \\
\hline & MLL3 & $\mathrm{H} 3 \mathrm{~K} 4$ \\
\hline & MLL4 & $\mathrm{H} 3 \mathrm{~K} 4$ \\
\hline & MLL5 & $\mathrm{H} 3 \mathrm{~K} 4$ \\
\hline & SET1A & $\mathrm{H} 3 \mathrm{~K} 4$ \\
\hline & SET1B & $\mathrm{H} 3 \mathrm{~K} 4$ \\
\hline & ASH1 & $\mathrm{H} 3 \mathrm{~K} 4$ \\
\hline & $\mathrm{Sc} / \mathrm{Sp}$ SET1 & $\mathrm{H} 3 \mathrm{~K} 4$ \\
\hline & SET2 (Sc/Sp SET2) & H3K36 \\
\hline & NSD1 & H3K36 \\
\hline & SYMD2 & H3K36 \\
\hline & DOT1 & H3K79 \\
\hline & Sc/Sp DOT1 & H3K79 \\
\hline & Pr-SET 7/8 & $\mathrm{H} 4 \mathrm{~K} 20$ \\
\hline & SUV4 20H1 & $\mathrm{H} 4 \mathrm{~K} 20$ \\
\hline & SUV4 $20 \mathrm{H} 2$ & $\mathrm{H} 4 \mathrm{~K} 20$ \\
\hline & SpSet 9 & $\mathrm{H} 4 \mathrm{~K} 20$ \\
\hline & EZH2 & H3К27 \\
\hline & RIZ1 & $\mathrm{H} 3 \mathrm{~K} 9$ \\
\hline \multirow{9}{*}{ 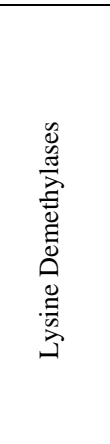 } & LSD1BHC110 & $\mathrm{H} 3 \mathrm{~K} 4$ \\
\hline & JHDM1a & H3К36 \\
\hline & JHDM1b & $\mathrm{H} 3 \mathrm{~K} 36$ \\
\hline & JHDM2a & $\mathrm{H} 3 \mathrm{~K} 9$ \\
\hline & JHDM2b & H3K9 \\
\hline & JMJD2A/JHDM3A & Н3К9, Н3К36 \\
\hline & JMJD2B & H3K9 \\
\hline & JMJD2C/GASC1 & H3K9, Н3К36 \\
\hline & JMJD2D & H3K9 \\
\hline \multirow{3}{*}{ 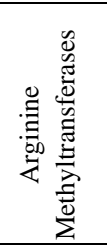 } & CARM1 & H3 (R2, R17, R26) \\
\hline & PRMT4 & H4R3 \\
\hline & PRMT5 & H3R8, H4R3 \\
\hline \multirow{5}{*}{ 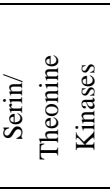 } & Haspin & H3T3 \\
\hline & MSK1 & $\mathrm{H} 3 \mathrm{~S} 28$ \\
\hline & MSK2 & $\mathrm{H} 3 \mathrm{~S} 28$ \\
\hline & CKII & H4S1 \\
\hline & Mst1 & H2BS14 \\
\hline \multirow{2}{*}{ 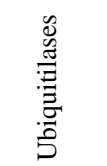 } & Bmi/Ring1A & H2AK119 \\
\hline & RNF20/RNF40 & $\mathrm{H} 2 \mathrm{BK} 120$ \\
\hline
\end{tabular}

Many researches in the epigenetics field mainly focus on human health care issues including embryonic development, aging and formation of a broad range of diseases such as varied types of cancer, type 2 diabetes mellitus, obesity, inflammation, cardiovascular diseases and neurocognitive disorders. Epigenetics is also thought as one of the best candidates for explanation of the unknown etiology of many human diseases. According to these frames, it is getting clear that a better understanding of epigenetic rules and related mechanisms will lead up to get more comprehensive and efficient results in the prevention and treatment strategies [21]-[23].

TABLE IV: SEVERAL EXAMPLES FOR EPIGENETIC DRUGS [21]

\begin{tabular}{ll}
\hline \hline Target & Drug \\
\hline \hline & 5-Azacytidine \\
& 5-Aza-2'-deoxycytidine \\
& 5-fluoro-2'-deoxycytidine \\
& Zebularine \\
DNA methylation & Procainamide \\
& Epigallocatechin-3-gallate \\
& Psammaplin A \\
& Antisense oligomers \\
& Phenylbutyric acid \\
& Suberoylanilide hydroxamic acid \\
Histone deacetylase & Depsipeptide \\
& Valproic acid \\
\hline \hline
\end{tabular}

Current status of knowledge on the epigenetic mechanisms enables development of promising strategies against many of human disorders related to phenotypic alterations occurring under environmental conditions and independent genomic sequence changes. In this manner, reversibility of epigenetic alterations is the most highlighted property, which provides a possibility to envisage the novel drug approaches in biotechnology for the future. This is called as "Epigenetic Therapy" and several examples for the drugs are presented in Table III and Table IV. Moreover, determination of epigenetic modifications on a specific gene or a region of chromatin material can be used as a diagnostic marker for the screening and prognosis of the related diseases [21]-[23].

On the other hand, epigenetics-associated studies have become exceptionally important in the nutritional field and food science because several nutrients may affect epigenetic patterns of an organism, resulting in a significant alteration in the gene expression levels, which may cause modifications in health-related phenotypes. This new field is called as nutritional epigenetics [24], [25].

Nutritional epigenetics fundamentally focuses on the alterative capabilities of nutrients and bioactive food components on the epigenetic phenomena. According to the recent advances in this field, several nutritive compounds such as folate, vitamin B-12, biotin, niacin, pantothenic acid, methionine, choline, genistein, tea catechin, resveratrol, butyrate, sulforaphane, diallyl sulfide and betaine were determined as efficient components on epigenetic mechanisms. With reference to current knowledge, any of these compounds may affect epigenetic pattern via acting two different ways. In the first proposed mechanism, a nutrient can act as a substrate for the enzymes associated with epigenetic regulation, but as an inhibitor in the second mechanism. For example, biotin is a substrate of histone biotinylation and curcumin is an inhibitor of histone acetyltransferases [24], [25].

Nevertheless, the knowledge of nutritional epigenetics is still insufficient and limited. Moreover, exact effect mechanisms of many bioactive substances also are unclear. However, the count of identified ones related to epigenetic mechanisms is drastically increasing by the development of 
novel technologies and new research strategies [24], [25]. In this manner, several examples for identified active nutrients and their effect mechanisms are shown in Table V.

TABLE V: SEVERAL EXAMPLES FOR NUTRITIONAL EPIGENETICS [24]

\begin{tabular}{|c|c|c|}
\hline & Nutrient or diet & $\begin{array}{l}\text { Epigenetic } \\
\text { mechanism }\end{array}$ \\
\hline \multirow{4}{*}{ 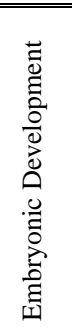 } & Folate & $\begin{array}{l}\text { DNA methylation } \\
\text { Imprinting }\end{array}$ \\
\hline & Choline & DNA methylation \\
\hline & Protein restriction & $\begin{array}{l}\text { DNA methylation } \\
\text { Histone }\end{array}$ \\
\hline & Alcohol & $\begin{array}{l}\text { modifications } \\
\text { DNA methylation }\end{array}$ \\
\hline \multirow{2}{*}{ 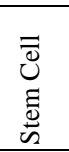 } & Butyrate & $\begin{array}{l}\text { Histone acetylation } \\
\text { DNA methylation }\end{array}$ \\
\hline & Retinoic acid & PRC \\
\hline \multirow{2}{*}{$\stackrel{50}{:}$} & Folate & DNA methylation \\
\hline & Calorie restriction & Histone acetylation \\
\hline 咅 总 & Folate & DNA methylation \\
\hline \multirow{4}{*}{ 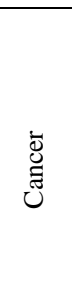 } & Methyl-deficient diet & $\begin{array}{l}\text { Histone } \\
\text { modification } \\
\text { MicroRNA }\end{array}$ \\
\hline & & $\begin{array}{l}\text { DNA methylation } \\
\text { MicroRNA }\end{array}$ \\
\hline & (一)-Epigallocatechin-3-gallate & $\begin{array}{l}\text { DNA methylation } \\
\text { PRC }\end{array}$ \\
\hline & Curcumin & MicroRNA \\
\hline \multirow{3}{*}{ 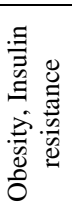 } & High-fat diet & $\begin{array}{l}\text { DNA methylation } \\
\text { MicroRNA }\end{array}$ \\
\hline & Methyl-deficient diet & DNA methylation \\
\hline & Curcumin & Histone acetylation \\
\hline \multirow{3}{*}{ 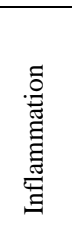 } & Resveratrol & Histone acetylation \\
\hline & AdoMet & $\begin{array}{l}\text { Histone } \\
\text { methylation }\end{array}$ \\
\hline & Methyl-deficient diet & MicroRNA \\
\hline 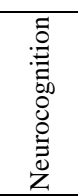 & Choline & $\begin{array}{l}\text { DNA methylation } \\
\text { Histone } \\
\text { methylation }\end{array}$ \\
\hline
\end{tabular}

\section{CONCLUSION}

Recently epigenetics has been one of the most promising fields in biotechnology and food science. Reversibility of its mechanisms enables improvement of new prevention and therapy strategies against several human disorders associated with epigenetic phenomenon regulated by various environmental factors.

Among all the external stimuli that cause epigenetic changes, nutrition has been the most attractive one due to its huge place in the human lifetime. Up to date, its role in embryonic development, stem cell differentiation, aging, immune response and formation of several human diseases has been intensively studied. The count of related studies has been also increasing day by day.

In a conclusion, epigenetics will be an essential and inevitable in the near future. Its potential in development of health-related applications is clear. As a consequence, epigenetics can be thought as an innovative approach for biotechnology and food science.

\section{REFERENCES}

[1] G. Felsenfeld, “A Brief History of Epigenetics," in Epigenetics, C. D. Allis, T. Jenuwein, D. Reinberg, and M. L. Caparros, Ed., New York: Cold Spring Harbor Laboratory Press, 2007, ch. 2, pp. 15-23.

[2] M. Esteller, "An Introduction to Epigenetics," in Epigenetics in Biology and Medicine, M. Esteller, Ed., New York: CRC Press, 2008, ch. 1 , pp. 1.

[3] S. Friso and S. W. Choi, "Introduction," in Nutrients and Epigenetics, S. W. Choi and S. Friso, Ed., New York: CRC Press, 2009, ch. 1, pp. 1-6.

[4] T. O. Tollefsbol, "Epigenetics: The New Science of Genetics," in Handbook of Epigenetics-The New Molecular and Medical Genetics, T. O. Tollefsbol, Ed., San Diego: Academic Press, 2011, ch. 1, pp. 1-6.

[5] C. Lu and C. B. Thomson, "Metabolic Regulation of Epigenetics," Cell Metabolism, vol. 16, pp. 9-17, July 2012.

[6] M. İzmirli, "Epigenetik Mekanizmalar ve Kanser Tedavisinde Epigenetik Yaklaşımlar (Epigenetic Mechanisms and Approaches in Cancer Treatment)," Van Med. J., vol. 20, pp. 48-51, January 2013.

[7] R. Holliday, "Epigenetics: A Historical Overview," Epigenetics, vol. 1, pp. 76-80, June 2006.

[8] Z. Herceg and R. Murr, "Mechanisms of Histone Modifications," in Handbook of Epigenetics-The New Molecular and Medical Genetics, T. O. Tollefsbol, Ed., San Diego: Academic Press, 2011, ch. 3, pp. $25-45$.

[9] D. M. Bond and E. J. Finnegan, "Passing the Message on: Inheritance of Epigenetic Traits," Trends Plant Sci., vol. 12, pp. 211-216, April 2007.

[10] C. V. Segré and S. Chiocca, "Regulating the Regulators: The Post-Translational Code of Class I HDAC1 and HDAC2," J. Biomed. Biotech., vol. 2011, pp. 1-15, October 2011.

[11] G. Schnitzler, "Chromatin Remodeling and Histone Modifications," in Nutrients and Epigenetics, S. W. Choi and S. Friso, Ed., New York: CRC Press, 2009, ch. 4, pp. 67-104.

[12] C. Martin and Y. Zhang, "Mechanisms of epigenetic inheritance," Curr. Opin. Cell Biol., vol. 19, pp. 266-272, June 2007.

[13] J. Ford, S. Ahmed, S. Allison, M. Jiang, and J. Milner, "JNK2-dependent Regulation of SIRT-1 Protein Stability," Cell Cycle, vol. 7, pp. 3091-3097, October 2008.

[14] A. Nott, P. M. Watson, J. D. Robinson, L. Crepaldi and A. Riccio, "S-nitrosylation of histone deacetylase 2 induces chromatin remodelling in neurons," Nature, vol. 455, pp.411-415, September 2008.

[15] D. T. Hess and J. S. Stamler, "Regulation by S-Nitrosylation of Protein Post-translational Modification," J. Biol. Chem., vol. 287, pp. 4411-4418, February 2012.

[16] A. Hershko and A. Ciechanover, "The Ubiquitin System," Annu. Rev. Biochem., vol. 67, pp. 425-479, July 1998.

[17] Y. Yang, W. Fu, J. Chen, N. Olashaw, X. Zhang, S. V. Nicosia, K. Bhalla, and W. Bai, "SIRT1 sumoylation regulates its deacetylase activity and cellular response to genotoxic stress," Nat. Cell Biol., vol. 9, pp. 1253-1262, November 2007.

[18] D. Jia and X. Cheng, "Methylation on the Nucleosome," in Nutrients and Epigenetics, S. W. Choi and S. Friso, Ed., New York: CRC Press, 2009, ch. 2, pp. 7-36.

[19] M. J. Boland and J. K. Christman, "Mammalian DNA methyltransferases," in Nutrients and Epigenetics, S. W. Choi and S. Friso, Ed., New York: CRC Press, 2009, ch. 3, pp. 37-66.

[20] T. Kouzarides, "Chromatin Modifications and Their Function," Cell, vol. 128, pp.693-705, February 2007.

[21] G. Egger, G. Liang, A. Aparicio, and P. A. Jones, "Epigenetics in human disease and prospects for epigenetic therapy," Nature, vol. 429, pp. 457-463, May 2004.

[22] S. Tyagi, R. Tyagi, and V. Tyagi, "Potential Medical Applications of Epigenetics: An Overview." Int. J. Pharmaceut. Sci. Rev. Res., vol. 3, pp. 143-147, August 2010.

[23] Y. Yang and G. Oh, "Applications of Epigenetic Technologies in the Understanding of Complex Diseases," JULS, vol. 4, pp. 90-95, March 2010 . 
[24] S. W. Choi and S. Friso, "Epigenetics: A New Bridge between Nutrition and Health," Adv. Nutr., vol. 1, pp. 8-16, November 2010.

[25] L. J. Su, S. Mahabir, G. L. Ellison, L. A. McGuinn, and B. C. Reid, "Epigenetic contributions to the relationship between cancer and dietary intake of nutrients, bioactive food components, and environmental toxicants," Frontiers in Genetics, vol. 2, pp. 1-12, January 2012.

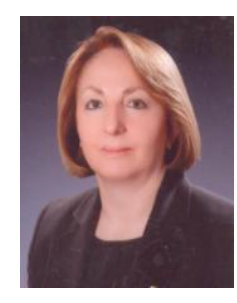

Medine Gulluce was born in Turkey in 1962. She received her bachelor's degree in biology (İstanbul University, Turkey) in 1984, her master's degree in the Health Sciences Institute (Atatürk University, Turkey) in 1988, and her PhD degree in the Health Sciences Institute (Kafkas University, Turkey) in 1993

She is currently working as a professor in the Biology Department of Atatürk University. Her research interest includes molecular biology, microbiology, immunology, genotoxicology, epigenetics, biotechnology, food science and renewable bioenergy. She has a lot of publications in these fields.

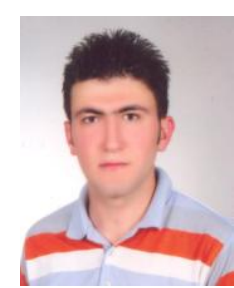

Burak Alaylar was born in Turkey in 1987. He graduated his bachelor degree in Biology Department of Atatürk University (Erzurum-Turkey) in 2011. He is a master student in the Graduate School of Natural and Applied Sciences (Atatürk University) and working on Epigenetics. His research interest includes molecular biology, microbiology, and epigenetics, especially DNA methylation analysis in yeast species.

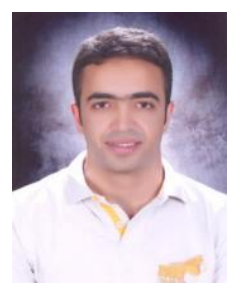

Taha Yasin Koc was born in Turkey in 1986. He graduated his bachelor degree in Biology Department of Atatürk University (Erzurum TURKEY) in 2011. He is a master student in the Graduate School of Natural and Applied Sciences (Atatürk University) and working on Epigenetics. His research interest includes molecular biology, microbiology, and epigenetics, especially DNA methylation analysis in prokaryotic microorganisms.

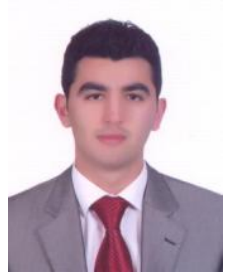

Mehmet Karadayi was born in Bulgaria in 1985 He graduated his bachelor degree in Biology Department of Atatürk University (Erzurum-Turkey) in 2006, and finished his master degree on Molecular Biology in the Graduate School of Natural and Applied Sciences (Atatürk University) in 2010 . He is a $\mathrm{PhD}$ student in the Graduate School of Natural and Applied Sciences (Atatürk University).

$\mathrm{He}$ is also currently working as a researcher assistant in the Biology Department of the same university. His research interest includes molecular biology, microbiology, genotoxicology, epigenetics, biotechnology, and renewable bioenergy and he has many publications in these fields. 